\title{
Heritability of Self-reported Phobic Fear
}

\author{
Marijn A. Distel · Jacqueline M. Vink · Gonneke Willemsen • \\ Christel M. Middeldorp · Harald L. G. J. Merckelbach · Dorret I. Boomsma
}

Received: 10 October 2007/Accepted: 19 October 2007/Published online: 12 December 2007

(C) The Author(s) 2007

\begin{abstract}
Twin studies on fear and phobia suggest moderate genetic effects. However, results are inconclusive regarding the presence of dominant genetic effects and sex differences. Using an extended twin design, including male and female twins $(n=5,465)$ and their siblings $(n=1,624)$, we examined the genetic and environmental influences on blood-injury, social, and agoraphobic fear and investigated their interaction with sex and age. Data of spouses $(n=708)$ of twins were used to evaluate assortative mating for the three fear dimensions. Results showed that there was no assortative mating for blood-injury, social and agoraphobic fear. Resemblance between biological relatives could be explained by additive and non-additive genetic effects for blood-injury and agoraphobic fear in all participants, and social fear in participants aged 14-25 years. For social fear in participants aged 26-65 only additive genetic effects were detected. Broad-sense heritability estimates ranged from 36 to $51 \%$ and were similar for men and women.
\end{abstract}

Keywords Fear - Genetics - Twin-family study · Assortative mating $\cdot$ Dominance

Edited by John K Hewitt.

M. A. Distel (ه) · J. M. Vink · G. Willemsen ·

C. M. Middeldorp · D. I. Boomsma

Department of Biological Psychology, VU University,

van der Boechorststraat 1, Amsterdam 1081 BT,

The Netherlands

e-mail: ma.distel@psy.vu.nl

H. L. G. J. Merckelbach

Faculty of Psychology, Maastricht University, Maastricht,

The Netherlands

\section{Introduction}

Fears and phobias are extremely disruptive and distressing disorders that have a great impact on an individual's life (Mendlowicz and Stein 2000; Saarni et al. 2007). The prevalence of anxiety disorders is high and anxiety disorders represent a serious public health concern (Kessler et al. 2005). However, the etiology of phobic fear is still poorly understood.

Family studies of clinically defined phobias have consistently found evidence for the familial aggregation (Fyer et al. 1995; Stein et al. 2001). Twin family studies of clinically defined fears and phobias have also indicated familiarity (Torgersen 1983; Skre et al. 1993; Skre et al. 2000). Due to their relatively small sample sizes, clinical studies often are unable to establish whether this familiarity results from genetic or environmental similarities. Through community based twin and twin family studies, large samples can be assessed, resulting in sufficient power to disentangle genetic and environmental influences in the etiology of fears and phobias. Such studies have suggested an important role for genetic and unique environmental factors (e.g., aversive experiences) in the origin of fears and phobias, while shared environmental influences appeared to be of little etiological significance (Hettema et al. 2001; Sundet et al. 2003).

The Virginia Twin Registry investigated the familial aggregation of phobia diagnoses in a large adult sample. In women, heritability estimates of 39\% for agoraphobia and $30 \%$ for social phobia were found (Kendler et al. 1992). In men, these estimates were 37 and 20\% (Kendler et al. 2001). Familial aggregation of blood-, needles-, hospital-, or illness-phobia was studied in female twins only and appeared to be due to shared environmental factors, although the statistical power to differentiate between 
additive genetic and common environmental influences was low (Neale et al. 1994a). An Australian study of selfreported fear of blood-injury-injection in female twins also found significant familial aggregation of blood-injuryinjection fears. It was not possible to differentiate between genetic and shared environmental influences as the explanation for familial aggregation. Multivariate genetic analysis of fainting and blood-injury-injection fear with and without fainting indicated that the genetic variance in bloodinjury-injection fear was attributable to additive genetic factors shared with fainting (55\%) (Page and Martin 1998).

Based on the correlation structure several studies suggested the presence of non-additive genetic effects in phobic fear, but due to insufficient statistical power, these effects could not convincingly be demonstrated (Skre et al. 2000; Neale et al. 1994a; Rose and Ditto 1983; Kendler et al. 1999; Page and Martin 1998).

The heritability estimates reported in the Kendler et al. studies of female (1992) and male twins (2001) seem to indicate lower heritability estimates for fear in men than in women. Together with the fact that women display generally more phobias than men (Fredrikson et al. 1996; Furmark 2002; Bekker 1996; Curtis et al. 1998; Bijl et al. 2002; Middeldorp et al. 2005) this suggests that men and women differ in the extent to which genetic and environmental risk factors affect phobic fear. Sex differences in the genetic contribution to the etiology of phobic fear have only been formally tested in the Virginia Twin Registry, in the Netherlands Twin Register and in the Australian Twin Registry. In the Virginia Twin Registry, Kendler et al. (2002) found equal heritability in men and women for agoraphobia and blood-injury phobia. For social phobia, on the other hand, resemblance in men was explained by genetic factors while in women resemblance was explained by shared environment. Because earlier studies relying on a female sample (Kendler et al. 1992, 1999) indicated that familial resemblance was entirely due to genetic factors, the authors attributed this sex difference to stochastic factors. However, results from two multivariate studies using data from the Virginia Twin Registry (Hettema et al. 2005, 2006), indicated that around $10 \%$ of the variance in social phobia was explained by shared environmental factors.

Qualitative sex differences on the liability for agoraphobia, social phobia and blood-injury phobia were suggested by Kendler et al. (2002) based on the dizygotic opposite sex (DOS) twin correlation, which was lower than the dizygotic (DZ) same sex correlations. A second study of the Virginia Twin Registry (Hettema et al. 2005) found no sex differences in the genetic and environmental risk factors for agoraphobia or social phobia. In a combined Dutch and Australian sample, Middeldorp et al. (2005) failed to find quantitative sex differences in the familial influences on agoraphobia and social phobia. For agoraphobia a low correlation in DOS twins suggested qualitative sex differences. To summarize, most studies report no sex differences in the heritability of fear and phobia while some do suggest qualitative sex differences based on the DOS and DZ correlation structure.

Spousal resemblance is often found for psychiatric disorders and related phenotypic traits. The most cited explanation for spousal similarity is assortative mating, meaning that spouses are more similar for a trait or disorder than expected under random mating (Merikangas 1982; Garrison et al. 1968), although significant spousal correlation could also indicate, for example, marital interaction or social stratification. Spousal resemblance is an important issue to consider because increased phenotypic correlation between spouses increases genetic variance in the offspring generation. When non-random mating for a heritable trait is present but this is not specifically included in the twin model, heritability estimates may be downwardly biased. For depressive disorders, a meta-analysis reported marital resemblance for depression in 12 of 17 studies (Mathews and Reus 2001). An extensive study on spousal similarity for psychiatric disorders in a population-based sample was carried out by Maes et al. (1998). Several psychiatric diagnoses were examined, including generalized anxiety disorder, major depressive disorder, panic disorder and phobias. Moderate spousal correlations were seen for most psychiatric diagnoses, but for phobias spousal correlations were not significant.

So far, age effects on the heritability of phobic fears have not received much attention in the literature. This is an omission because it has well been established that some specific fears decline from adolescence to later life (e.g., fear of blood, strangers or personal death) (Bienvenu and Eaton 1998; Hall 1897; Rose and Ditto 1983; Kessler et al. 1994; Henderson et al. 1998), while others increase or are not affected by age at all (e.g., fear of negative social interactions or small organisms) (Rose and Ditto 1983; Lapouse and Monk 1959). Rose and Ditto (1983) found evidence that with age there is a change in the genetic and environmental influences on fear of death. However, a more recent study reported that there were hardly any longitudinal changes in the genetic and environmental determinants of anxiety (Gillespie et al. 2004).

In order to replicate and extend previous research on fears and phobias, we examined the heritability of three classes of phobic fears (i.e., blood-injury, social, and agoraphobic fear) using longitudinal data from Dutch twins and their siblings registered with the Netherlands Twin Register (Boomsma et al. 2006). The inclusion of siblings and repeated observations increases statistical power to discriminate between additive genetic and non-additive genetic effects and to detect sex specific genetic effects. Adding siblings to the sample also provides the opportunity 
to examine twin-specific effects on phobic fears (Posthuma and Boomsma 1999, 2000). Data were also available for a subsample of spouses of twins which were used to estimate the correlation between spouses to examine whether there is evidence for assortative mating. Since the determinants of phobic fear in adolescence and young adulthood may differ from those in later life, we divided the dataset into two age cohorts so as to test for differences in heritability between the two cohorts. In addition, we tested for qualitative and quantitative sex differences in the etiology of phobic fear.

To summarize, in this report, we address the following questions. First, is there spousal similarity for blood-injury, social and agoraphobic fear? Second, what are the heritability estimates for these three subtypes of fear? Third, are there sex and age differences in the heritability estimates of these subtypes?

\section{Methods}

\section{Participants}

This study is part of an ongoing study on health and lifestyle in twin families registered with the Netherlands Twin Register (Boomsma et al. 2006). Initially, adolescent and adult twins and their family members were recruited through City Councils in 1990-91 and in 1992-93. After 1993, an effort was made to recruit older twins through a variety of approaches. Siblings and spouses of twins were recruited in the study since 1995 and 2000, respectively. Parents did not participate in 1997 and 2000. All registered individuals gave their informed consent before they filled out questionnaires. Further details on response rates and demographic characteristics of the sample can be found elsewhere (Boomsma et al. 2002; Vink et al. 2004; Boomsma et al. 2006). The data on phobic fear were derived from surveys sent in 1997 and 2000. Table 1 shows the complete sample configuration of two age cohorts in 1997 and 2000. In total, there were 7,089 subjects $(5,465$ twins and 1,624 siblings) from 3,471 families, with longitudinal data available for 2,537 individuals. Based on the age of the twins, we subdivided the participating families into two age groups: a $14-25$ year group ( $n=4,275$ individuals) and a 26-65 year group ( $n=2,814$ individuals). Families with siblings but without twins were assigned to one of the two age groups according to the age of the youngest sibling. There was a small overlap between the two age cohorts in age of the non-twin siblings. In the 14-25 year age group, there were 1,987 families of which 1,004 included one or more family members who participated at both time points. The 26-65 year age group involved 1,484 families of which 435 contained one or more family members who participated at both time points. In the youngest age group, mean age was 21.2 years $(\mathrm{SD}=3.5)$ in 1997 and 23.2 years $(\mathrm{SD}=3.6)$ in 2000 . In the oldest age group, mean age was 36.6 years $(S D=10.5)$ in 1997 and 38.0 years $(S D=10.4)$ in 2000 . For the 2000 survey, we asked spouses of all twins aged 25-30 years to participate. In total 708 spouses completed a survey.

\section{Zygosity}

A total of 1,322 twins were classified as DZ because they were of opposite sex. Zygosity of same sex twins was determined from DNA polymorphisms $(n=1,205)$, or from survey questions about physical twin resemblance and confusion of the twins $(n=2,938)$. Based on the answers from all available surveys, zygosity was determined. When there was an inconsistency over time or persons, the majority of the judgements determined the final outcome. The agreement between zygosity based on survey data and on DNA typing was $97 \%$ (Willemsen et al. 2005).

\section{Measures}

Participants completed the Dutch version of the Fear Questionnaire (FQ; Marks and Mathews 1979). The FQ is a widely used instrument that possesses good psychometric qualities (Van Zuuren 1988). The FQ contains 15 items that tap phobic avoidance in three domains: blood-injury fear (e.g., avoidance of hospitals), social fear (e.g., avoiding talking to people in authority), and agoraphobic fear (e.g., avoiding large, open spaces). Each domain is represented with five items. Subjects were instructed to indicate on a nine point scale ( 0 'would not avoid it' to 8 'always avoid it') how much they would avoid certain situations because of fear or other unpleasant feelings. Scores were summed across subscales to obtain scores for blood-injury fear, social fear, and agoraphobic fear. A score was only calculated if at least four out of five items of a subscale were answered. Missing answers and double entries were substituted by the mean item score. We checked the factor structure of the FQ in our sample. All items of the FQ were analyzed with PCA with promax rotation in SPSS. Analyses were done separately for the two time points with random selection of one person per family. At both time points we found the original three factor solution in our data which accounted for around $47 \%$ of the variance.

\section{Twin-family Studies}

Twin studies make use of the genetic relatedness of twins and their family members to address questions about the 
Table 1 Family configuration in the sample according to zygosity, cohort and number of additional non-twin siblings of the two time points (separated by the slash; 1997/2000)

\begin{tabular}{|c|c|c|c|c|c|c|}
\hline & & Zero siblings & Brother & Sister & Brother and Sister & Total \\
\hline \multicolumn{7}{|l|}{ Age 14-25 } \\
\hline \multirow[t]{2}{*}{ MZM } & Twin pair & $70 / 104$ & $41 / 29$ & $35 / 27$ & $9 / 4$ & $155 / 164$ \\
\hline & Single twin & $21 / 57$ & $4 / 6$ & $10 / 11$ & $1 / 3$ & $36 / 77$ \\
\hline \multirow[t]{2}{*}{ DZM } & Twin pair & $44 / 45$ & $33 / 15$ & $26 / 14$ & $3 / 7$ & $106 / 81$ \\
\hline & Single twin & $18 / 44$ & $4 / 9$ & $10 / 10$ & $1 / 2$ & $33 / 65$ \\
\hline \multirow[t]{2}{*}{ MZF } & Twin pair & $145 / 230$ & $49 / 35$ & $62 / 56$ & $12 / 9$ & $268 / 330$ \\
\hline & Single twin & $49 / 106$ & $10 / 12$ & $11 / 17$ & $3 / 2$ & $73 / 137$ \\
\hline \multirow[t]{2}{*}{$\mathrm{DZF}$} & Twin pair & $84 / 108$ & $34 / 19$ & $37 / 27$ & $7 / 7$ & $162 / 161$ \\
\hline & Single twin & $33 / 87$ & $10 / 9$ & $12 / 23$ & $2 / 2$ & $57 / 121$ \\
\hline \multirow[t]{2}{*}{ DOS } & Twin pair & $101 / 105$ & $64 / 37$ & $68 / 41$ & $10 / 3$ & $243 / 186$ \\
\hline & Single twin & $69 / 183$ & $11 / 26$ & $25 / 32$ & $6 / 2$ & $111 / 243$ \\
\hline No twins & & & $23 / 43$ & $38 / 72$ & $2 / 4$ & $63 / 119$ \\
\hline Total age $14-25$ & & $634 / 1069$ & $283 / 240$ & $334 / 330$ & $56 / 45$ & $1307 / 1684$ \\
\hline \multicolumn{7}{|l|}{ Age 26-65 } \\
\hline \multirow[t]{2}{*}{ MZM } & Twin pair & $16 / 60$ & $8 / 6$ & $7 / 11$ & $5 / 8$ & $36 / 85$ \\
\hline & Single twin & $20 / 68$ & $6 / 3$ & $4 / 7$ & $6 / 1$ & $36 / 79$ \\
\hline \multirow[t]{2}{*}{ DZM } & Twin pair & $11 / 31$ & $3 / 6$ & $3 / 7$ & $7 / 3$ & $24 / 47$ \\
\hline & Single twin & $20 / 54$ & $4 / 2$ & $7 / 5$ & $5 / 5$ & $36 / 66$ \\
\hline \multirow[t]{2}{*}{ MZF } & Twin pair & $64 / 223$ & $14 / 22$ & $23 / 53$ & $9 / 12$ & $110 / 310$ \\
\hline & Single twin & $30 / 122$ & $6 / 10$ & $10 / 16$ & $2 / 4$ & $48 / 152$ \\
\hline \multirow[t]{2}{*}{ DZF } & Twin pair & 29/95 & $8 / 14$ & $11 / 15$ & $3 / 6$ & $51 / 130$ \\
\hline & Single twin & $39 / 99$ & $4 / 9$ & $14 / 7$ & $3 / 0$ & $60 / 115$ \\
\hline \multirow[t]{2}{*}{ DOS } & Twin pair & $27 / 86$ & $9 / 7$ & $10 / 15$ & $4 / 7$ & $50 / 115$ \\
\hline & Single twin & $36 / 120$ & $6 / 8$ & $10 / 22$ & $6 / 5$ & $58 / 155$ \\
\hline No twins & & & $21 / 44$ & $46 / 25$ & $12 / 8$ & $79 / 77$ \\
\hline Total age $26-65$ & & 292/958 & $89 / 131$ & $145 / 183$ & $62 / 59$ & $588 / 1331$ \\
\hline Total number of families & & $926 / 2027$ & $372 / 371$ & $479 / 513$ & $118 / 104$ & $1895 / 3015$ \\
\hline
\end{tabular}

MZM = monozygotic males; DZM = dizygotic males; MZF = monozygotic females; DZF = dizygotic females; DOS = dizygotic opposite sex twins

etiology of population variation. Monozygotic (MZ) twins are genetically (nearly) identical. Dizygotic (DZ) twins and siblings share on average $50 \%$ of their segregating genes. Additive genetic effects (A) are suggested if the correlation for a phenotype in $\mathrm{MZ}$ twins is larger than the correlation in DZ twins and siblings. When the DZ correlation is more than half the MZ correlation, this indicates environmental effects shared by members from the same family (C). When the DZ correlation is less than half the MZ correlation, this can be taken as evidence for non-additive genetic effects (D). Non-additive genetic effects can consist of interactions between alleles within a locus (dominance) or across different loci (epistasis). Differences in fear scores within MZ twin pairs are due to unique environmental influences (E), which also include measurement error. The observed variance in phobic fear can thus be decomposed in four possible sources of variance; $\mathrm{A}, \mathrm{C}, \mathrm{D}$, and $\mathrm{E}$. However, the observed variances and covariances only provide enough information to test either an ACE model or an ADE model. Based on the pattern of twin correlations (see results section), A, D, and $\mathrm{E}$ were modelled in this study.

\section{Statistical Analysis}

Since phobic fear is not normally distributed in the population we used a multiple threshold model (see Fig. 1) to estimate the genetic and environmental contributions to the liability of phobic fear. Liability to phobic fear is assumed to be continuous and normally distributed in the population. Derks et al. (2004) showed that this is the optimal approach when analyzing L-shaped distributed phenotypic data. We divided the liability to phobic fear in three categories separated by two thresholds so that all categories contained approximately equal numbers of subjects 


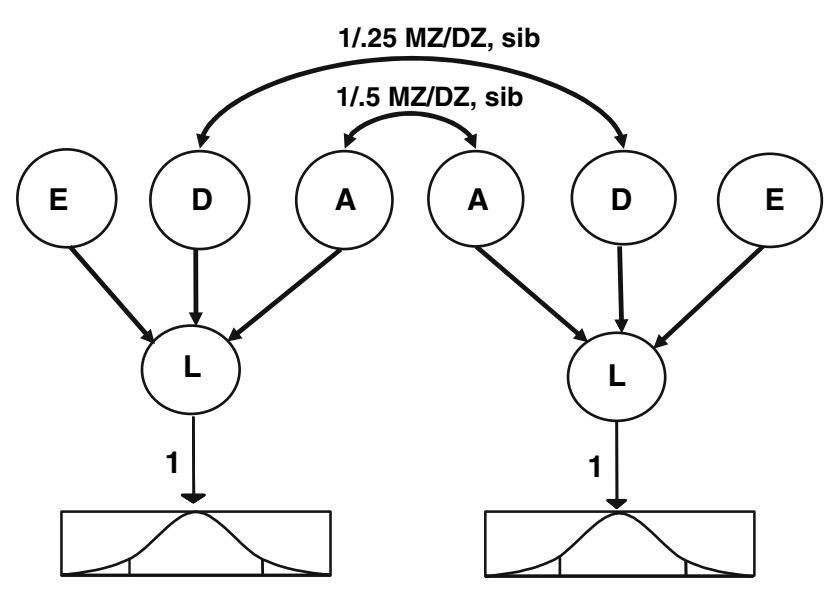

Fig. 1 Threshold model of the liability for phobic fear. Latent factors are symbolized in circles, observed phenotype as squares. E, unique environmental factor; D, non-additive genetic factor; A, additive genetic factor; L, liability for phobic fear. Latent factors can be correlated within families and influence the liability to phobic fear

(see Fig. 2). The validity of the bivariate threshold model to the fear data divided in three categories, was assessed in PRELIS (Jöreskog and Sörbom 1996). The fit of the bivariate threshold model to the blood-injury, social and agoraphobic fear data was good; almost all RMSEA's were $<0.05$ and all $P$ values exceeded the 0.002 significance level (Bonferroni correction for multiple testing).

Genetic structural equation modelling was carried out in Mx (Neale et al. 2003). Testing of submodels was done by means of likelihood-ratio tests, by subtracting the negative $\log$ likelihood ( $-2 \mathrm{LL})$ for the more restricted model from the $-2 \mathrm{LL}$ for the more general model. This yields a statistic that is distributed as $\chi^{2}$ with degrees of freedom (df) equal to the difference in the number of parameters in the two models. If the $\chi^{2}$-test yields a $P$-value higher than 0.05 , the constrained model is deemed not significantly worse than the previous model and is kept as the most parsimonious model to which the next model will be compared.

We started with fitting saturated models to describe the correlational structure between twin pairs and between siblings in each zygosity group. We used repeated measures from two time points (Rebollo and Boomsma 2006). Twin and sibling correlations were constrained to be equal at the two time points. For each fear subtype (blood-injury, social, and agoraphobic fear) and within each age group (14-25 and 26-65 years), we estimated five twin correlations (one for each sex by zygosity group) and three sibling correlations (male-male, female-female, and male-female sib pairs). Two cross-time within person correlations (one for each sex) and eight cross-twin cross-time correlations (one for each of the five sex by zygosity and the three sib pair groups) were estimated for each trait (not reported in the results section). Thresholds were estimated separately for men and women at each time point. The spouse correlations (Spearman's correlation coefficients) were calculated using SPSS 12.0 for windows.

First, we tested whether the resemblance in sibling pairs was the same as in dizygotic twin pairs. Next, quantitative sex differences were investigated by constraining the correlations for same-sex male twin pairs and same-sex female twin pairs to be equal. Qualitative sex differences were investigated by constraining the correlations for DZ samesex twin pairs and DZ opposite-sex twin pairs to be equal.

In a genetic model, the influence of latent factors A, D and $\mathrm{E}$ on the phobic fear score in 1997 and 2000 was estimated by the parameters (factor loadings) a, d, and e. The estimates for $\mathrm{a}, \mathrm{d}$ and e were constrained to be equal in 1997 and 2000 for all three fear subtypes because we assume that the same etiological mechanism influences phobic fear at both time points. Correlations between the latent $\mathrm{A}$ and $\mathrm{D}$ factors were fixed at 1 for $\mathrm{MZ}$ twins. For DZ twins and siblings, the correlations between the latent A factors were fixed at 0.5 , because they share on average half of their segregating genes. Dominant genetic effects result from the interaction or combination of alleles at a particular locus. Offspring receive only one allele from each parent and not a combination of two alleles. Parents and offspring share on average half of their genes so the chance that two siblings receive the same allele is $0.5 \times 0.5$ resulting in a correlation of 0.25 between the latent $\mathrm{D}$ factor for $\mathrm{DZ}$ twins and sibling pairs.

We first tested whether a, $d$ and e in the two age groups could be constrained to be equal. Next, different models (ADE, AE and E) were fitted to the data to test which sources of variance contribute to individual differences in phobic fear.

\section{Results}

Figure 2 shows the distribution of fear scores in 1997 for males and females aged 14-25 and aged 26-65. The 2000 scores (not presented here) show a similar pattern. Women had significantly more often high scores on each fear dimension than men in each age group, except for bloodinjury fear in the oldest age group for which there was no difference between men and women. There was no effect of age on the distribution of fear scores, except for women's scores on blood-injury fear, which were significantly higher in the youngest age group.

There was no significant correlation between twins and their spouses for blood-injury fear $\left(r_{s}=0.05, P=0.162\right)$, social fear $\left(r_{s}=0.04, P=0.324\right)$ or agoraphobic fear $\left(r_{s}=0.04, P=0.341\right)$.

Table 2 displays the twin correlations and confidence intervals for blood-injury, social, and agoraphobic fear for both age groups. Correlations for same sex DZ and DOS 
Fig. 2 Distribution of fear scores in 1997 for men and women age 14-25 and age $26-65$ years. The $Y$-axis gives the percentage of males and females with each score. The dashed lines indicate the thresholds

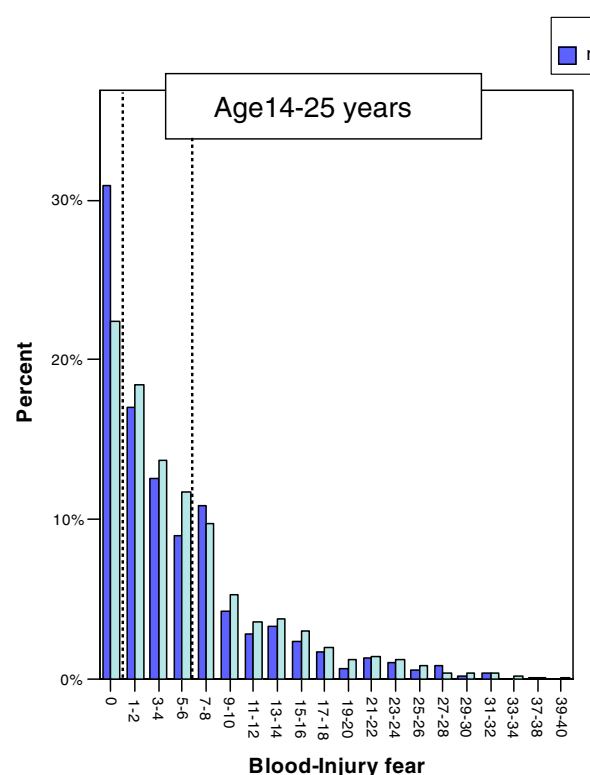

Sex

Sex $\square$ women
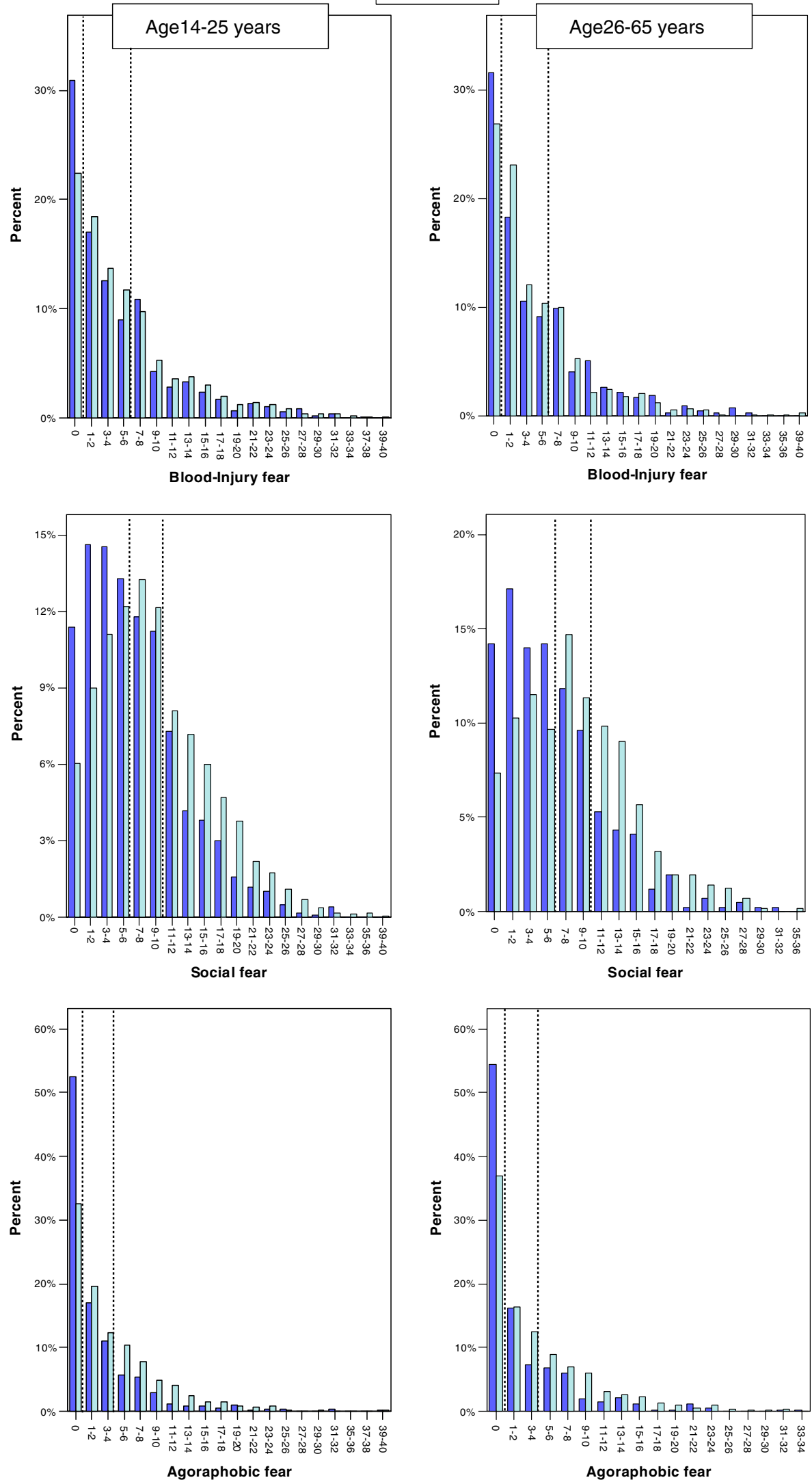

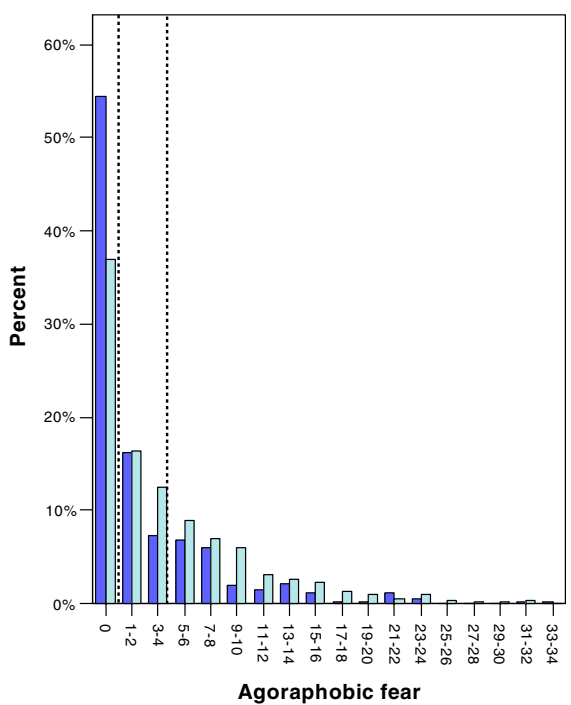


Table 2 Twin and sibling correlations for blood-injury, social and agoraphobic fear for age group 14-25 years and age group 26-65 years (95\% confidence intervals added in parentheses)

\begin{tabular}{|c|c|c|c|c|c|c|}
\hline & \multicolumn{2}{|l|}{ Blood-injury fear } & \multicolumn{2}{|l|}{ Social fear } & \multicolumn{2}{|l|}{ Agoraphobic fear } \\
\hline & Age $14-25$ & Age $26-65$ & Age $14-25$ & Age $26-65$ & Age $14-25$ & Age $26-65$ \\
\hline MZ males & $0.30(0.17-0.42)$ & $0.36(0.14-0.54)$ & $0.53(0.41-0.63)$ & $0.29(0.03-0.50)$ & $0.47(0.34-0.56)$ & $0.49(0.27-0.65)$ \\
\hline $\mathrm{DZ}$ males & $0.04(-0.16-0.22)$ & $-0.04(-0.32-0.25)$ & $0.15(-0.05-0.34)$ & $0.49(0.20-0.68)$ & $0.27(0.09-0.43)$ & $0.22(-0.10-0.48)$ \\
\hline MZ females & $0.34(0.25-0.43)$ & $0.41(0.32-0.50)$ & $0.48(0.39-0.56)$ & $0.42(0.31-0.52)$ & $0.40(0.30-0.48)$ & $0.37(0.26-0.47)$ \\
\hline DZ females & $0.18(0.05-0.30)$ & $0.11(-0.06-0.28)$ & $0.20(0.06-0.33)$ & $0.37(0.20-0.53)$ & $0.13(-0.00-0.26)$ & $0.27(0.08-0.44)$ \\
\hline DZ opposite sex & $0.23(0.10-0.34)$ & $0.16(-0.04-0.34)$ & $0.22(0.10-0.34)$ & $0.25(0.03-0.44)$ & $0.17(0.04-0.29)$ & $0.22(0.01-0.41)$ \\
\hline Brother-brother & $0.16(0.03-0.28)$ & $0.28(0.10-0.44)$ & $0.12(-0.02-0.25)$ & $0.19(-0.03-0.38)$ & $0.09(-0.04-0.22)$ & $-0.01(-0.24-0.22)$ \\
\hline Sister-sister & $0.10(-0.01-0.20)$ & $-0.02(-0.16-0.13)$ & $0.09(-0.03-0.20)$ & $0.14(-0.01-0.28)$ & $0.10(-0.01-0.19)$ & $0.12(-0.03-0.26)$ \\
\hline Brother-sister & $0.10(0.02-0.18)$ & $0.06(-0.05-0.17)$ & $0.15(0.06-0.23)$ & $0.11(-0.02-0.23)$ & $0.08(-0.00-0.02)$ & $0.07(-0.05-0.18)$ \\
\hline All $\mathrm{MZ}^{\mathrm{a}}$ & $0.33(0.26-0.40)$ & $0.39(0.30-0.48)$ & $0.50(0.43-0.56)$ & $0.40(0.30-0.49)$ & $0.42(0.35-0.49)$ & $0.39(0.30-0.48)$ \\
\hline All DZ/siblings ${ }^{\mathrm{a}}$ & $0.13(0.08-0.18)$ & $0.09(0.02-0.16)$ & $0.15(0.10-0.20)$ & $0.20(0.13-0.27)$ & $0.11(0.07-0.16)$ & $0.12(0.05-0.19)$ \\
\hline
\end{tabular}

$\mathrm{MZ}=$ monozygotic; $\mathrm{DZ}=$ dizygotic

${ }^{a}$ After constraining these correlations to be equal

twin pairs, and for sibling pairs could be constrained to be equal, suggesting that there is no evidence for a special twin environment. MZ male-male and female-female correlations were the same and DZ same-sex correlations were also the same, indicating that there are no quantitative sex differences in the influence of genetic effects on the three fear types. The DZ opposite-sex twin correlation was equal to the same-sex DZ correlation indicating that the same genes affect fear in men and women. After these constraints, MZ correlations were more than twice as large as the correlations for DZ twins and siblings suggesting that genetic effects contribute to individual differences in phobic fear and that these effects act in a partly nonadditive manner.

Model fitting results for blood-injury, social, and agoraphobic fear are shown in Table 3. The data from two age groups were simultaneously analysed in one model with different parameter estimates for the two age groups. For each fear subtype, a general ADE model (model 1) was fitted. Next, we tested if the A, D, and E components were the same for the two age cohorts (model 2). Finally, in model 3, and in the case of social fear in models 4 and 5, the significance of $\mathrm{D}$ and $\mathrm{A}$ in the two age groups was tested by constraining the relevant parameters at zero. For blood-injury and agoraphobic fear, this resulted in a model in which variance components did not differ between the two age groups. Non-additive genetic effects could not be left out of the model for blood-injury and agoraphobic fear. A, D and E explained respectively $9.9,25.6$, and $64.5 \%$ of the variance in blood-injury fear, and 10.7, 29.9, and 59.5\% of the variance in agoraphobic fear. For social fear in the youngest age group, A, D and E contributed to the
Table 3 Model fitting results for blood-injury, social, and agoraphobic fear; comparisons of models are shown

\begin{tabular}{|c|c|c|c|c|c|c|}
\hline Models & vs & $-2 \mathrm{LL}$ & $\mathrm{df}$ & $\Delta \mathrm{df}$ & $\Delta \chi^{2}$ & $P$ \\
\hline \multicolumn{7}{|l|}{ Blood-injury fear } \\
\hline 1. $\mathrm{ADE}$ & & 20254.58 & 9608 & & & \\
\hline 2. ADE no age diff. & 1 & 20257.23 & 9617 & 9 & 2.65 & 0.98 \\
\hline $\begin{array}{l}\text { 3. AE no age diff. } \\
\text { Social fear }\end{array}$ & 2 & 20415.27 & 9620 & 3 & 158.03 & 0.00 \\
\hline 1. $\mathrm{ADE}$ & & 19439.72 & 9608 & & & \\
\hline $\begin{array}{l}\text { 2. ADE no age diff. } \\
\text { 3. AE young }\end{array}$ & 1 & 19468.90 & 9617 & 9 & 29.18 & 0.00 \\
\hline $\begin{array}{l}\text { ADE old } \\
\text { 4. ADE young }\end{array}$ & 1 & 19454.05 & 9611 & 3 & 14.33 & 0.00 \\
\hline $\begin{array}{l}\text { AE old } \\
\text { 5. ADE young }\end{array}$ & 1 & 19439.72 & 9611 & 3 & 0.00 & 1.00 \\
\hline $\begin{array}{l}\text { E old } \\
\text { Agoraphobic fear }\end{array}$ & 4 & 19521.58 & 9614 & 3 & 81.87 & 0.00 \\
\hline 1. $\mathrm{ADE}$ & & 19967.61 & 9614 & & & \\
\hline 2. ADE no age diff. & 1 & 19973.66 & 9623 & 9 & 6.05 & 0.74 \\
\hline 3. AE no age diff. & 2 & 19984.90 & 9626 & 3 & 11.24 & 0.01 \\
\hline
\end{tabular}

vs $=$ versus and indicates which model the sub model is compared to; $-2 \mathrm{LL}=-2 \log$ likelihood; $\mathrm{df}=$ degrees of freedom

Most parsimonious solution per fear subtype is shown in bold

variance, and explained $7.8,42.9$, and $49.3 \%$ of the variance, respectively, while in the oldest age group D did not contribute to the variance. In fact, $40.3 \%$ of the variance in social fear in the oldest age group could be explained by additive genetic effects and $59.7 \%$ by unique environmental effects (Table 4). 
Table 4 Parameter estimates of the best-fitting models in age group 14-25 and age group 26-65 for blood-injury fear, social fear and agoraphobic fear

\begin{tabular}{lllll}
\hline & & $\mathrm{a}^{2}(\%)$ & $\mathrm{d}^{2}(\%)$ & $\mathrm{e}^{2}(\%)$ \\
\hline Blood-injury fear & Age 14-65 & 9.9 & 25.6 & 64.5 \\
Social fear & Age 14-25 & 7.8 & 42.9 & 49.3 \\
& Age 26-65 & 40.3 & - & 59.7 \\
Agoraphobic fear & Age 14-65 & 10.7 & 29.9 & 59.5 \\
\hline
\end{tabular}

$\mathrm{a}^{2}=$ additive genetic variance component; $\mathrm{d}^{2}=$ dominant genetic variance component; $\mathrm{e}^{2}=$ unique environmental variance component

\section{Comments}

This is the first study that explored the genetic and environmental contributions to individual differences in bloodinjury, social, and agoraphobic fear using an extended twin design. We tested whether there was evidence for assortative mating, for a specific twin environment, and if the impact of the genetic and environmental factors differed between men and women and between two age cohorts.

We observed that more women than men scored high on all fear dimensions, except for blood-injury fear in the oldest age group. This pattern is consistent with the large majority of studies that looked at sex differences in fear levels: overall, women tend to have higher scores on self-report measures tapping various fear categories, the exception being blood-injury phobia, where the sex distribution is somewhat more balanced (Bijl et al. 1998; Kessler et al. 1994; Middeldorp et al. 2005).

Prior studies showed that many fear types display a distinct developmental course, with, in general, a decline of fear levels from adolescence to later life. Our data suggest no large effect of age in fear scores: a pattern of declining fear scores was only seen for blood-injury fear, with younger participants having higher fear levels than older participants. This is in accordance with the literature (Bijl et al. 2002; Page 1994). However, many developmental changes in fear levels occur before the adolescent stage (Marks 1987), an underrepresented age group in our sample. Future research will have to determine whether changes in blood-injury, social and agoraphobic fear emerge before adolescence.

Spouse similarity is an important issue to consider when studying genetic influences on population variation. In accordance with what was reported previously for phobias (Maes et al. 1998) and anxiety disorders (Low et al. 2007), we did not find a significant association between spouses, indicating that there is random mating for blood-injury, social and agoraphobic fears.

Broad-sense heritability estimates for blood-injury, social, and agoraphobic fear were moderate ranging from
$35.5 \%$ (blood-injury fear) to $50.7 \%$ (social fear in the youngest age group). These heritability estimates for blood-injury fear and agoraphobic fear are comparable to the estimates reported by Kendler et al. (1992, 2001). The heritability estimate for social fear $(50.7 \%$ in the youngest age group and $40.3 \%$ in the oldest age group) was somewhat higher than that reported by Kendler et al. (30\% for women and $20 \%$ for men) but comparable to the heritability estimate found by Middeldorp et al. (2005) (50\%). Contrary to what was found by Hettema et al. (2005, 2006) shared environmental factors did not significantly contribute to the variance in social fear. All in all, these results confirm the conclusion of Kendler et al. (1992, p. 279) that "the estimated heritability of liability for phobias indicates that genetic factors play a significant, but by no means overwhelming role in the etiology of phobias."

In accordance with previous findings (Hettema et al. 2005; Middeldorp et al. 2005; Kendler et al. 2002), no differences in heritability between men and women were observed. Regarding qualitative sex differences, the results are somewhat different from previous studies. Whereas results of Kendler et al. (2002) and Middeldorp et al. (2005) suggested the presence of qualitative sex differences for agoraphobic fear, we did not find any evidence that different genes influence the liability of phobic fear in men and women. Since the sample in our study was enriched with siblings of twins, a large number of opposite sex first degree relatives was added to the study. These data do not indicate a lower familial correlation in opposite-sex relatives.

For all three fear subtypes, MZ correlations were more than twice as high as the DZ/sibling correlations, indicating that non-additive genetic effects may contribute to the variance in phobic fears. Several previous studies suggested the influence of non-additive genetic effects on fears and phobia, which makes sense because fears are likely to be exposed to selection during evolution. Skre et al. (2000) investigated the genetic and environmental contributions to common phobic fears in a treatment sample of 61 twin pairs and found the twin correlations for social fear to fit best to a model including non-additive genetic effects. For blood-injection-injury fear, the correlational structure found by Skre et al. suggested the influence of non-additive genetic effects but model fitting showed that due to violation of equal variances between $\mathrm{MZ}$ and $\mathrm{DZ}$ twins all variance was accounted for by unique environmental effects. Neale et al. (1994b) also reported evidence for non-additive genetic effects in reanalysing the Rose and Ditto data (1983) of common social fears. In addition, Kendler et al. (1999) found evidence for non-additive genetic effects in agoraphobia, but not in social phobia and blood-injury phobia, while Page and Martin (1998) suggested the possibility of non-additive genetic effects on the 
variance in blood-injury phobia. In 2002, Kendler et al. (2002) did not model non-additive genetic effects explicitly, yet the correlation structure did suggest the presence of non-additive genetic effects for agoraphobia and bloodinjury phobia. To summarize, many studies indicated the presence of non-additive genetic effects on the liability for fear and phobias but they often did not have sufficient statistical power to detect non-additive genetic effects. The large sample size of this study together with repeated measures enabled us to detect the influence of non-additive genetic effects on blood-injury fear, social fear (in the youngest age group), and agoraphobic fear, confirming the speculations discussed in previous studies. For social fear in the oldest age group, non-additive genetic effects were not detected. Thus, the mixture of genetic and environmental influences on social fear seems to differ between the two age cohorts, though the differences in correlation structure were small. These results could be relevant to gene mapping of anxiety and phobia. If many of the genes underlying anxiety and phobia have non-additive effects, as suggested by our results, then quantitative trait loci with little additive genetic effects may have been missed in linkage analysis (Purcell and Sham 2004). Explicitly modelling non-additive genetic effects may therefore be important in the linkage analysis of anxiety, fear and phobia.

In general, our data are well in line with the multifactorial model of fears and phobias (Muris and Merckelbach 2001). This model assumes that a genetic vulnerability predisposes individuals to develop maladaptive fears and that discrete learning experiences (i.e., unique environmental factors) in combination with genetic vulnerabilities produce persistent fears.

Results of this study should be interpreted in context of the following limitations. First, the present study relied on non-clinical groups, and, although there is no reason to assume that heritabilities increase at the extreme end of the fear continuum (Stevenson et al. 1992), it is important to replicate the findings in clinical samples. Second, data of our study were obtained with an instrument (i.e., the FQ) that primarily focuses on self-reported avoidance behavior related to a limited number of fear categories and our results may not be generalized to other specific fears such as fear of small animals.

In summary, we found random mating for blood-injury, social and agoraphobic fear. Individual differences in blood-injury fear and agoraphobic fear in both age groups and social fear in the youngest age group (14-25 years) could be explained by additive and non-additive genetic factors and unique environmental factors, while individual differences in social fear in the oldest age group (2665 years) could be explained by additive genetic and unique environmental factors. The heritability of the three fear subtypes was similar for men and women and no effects of sex-specific genes were detected.

Acknowledgments This project was supported by the Borderline Personality Disorder Research Foundation and the Netherlands Organisation for Scientific Research (NWO 904-61-090, 985-10-002, NWO-MagW 480-04-004 and NWO/SPI 56-464-14192).

Open Access This article is distributed under the terms of the Creative Commons Attribution Noncommercial License which permits any noncommercial use, distribution, and reproduction in any medium, provided the original author(s) and source are credited.

\section{References}

Bekker MHJ (1996) Agoraphobia and gender: a review. Clin Psychol Rev 16:129-146

Bienvenu OJ, Eaton WW (1998) The epidemiology of bloodinjection-injury phobia. Psychol Med 28:1129-1136

Bijl RV, de Graaf R, Ravelli A, Smit F, Vollebergh WAM (2002) Gender and age-specific first incidence of DSM-III-R psychiatric disorders in the general population - results from the Netherlands Mental Health Survey and Incidence Study (NEMESIS). Soc Psychiatry Psychiatr Epidemiol 37:372-379

Bijl RV, Ravelli A, van Zessen G (1998) Prevalence of psychiatric disorder in the general population: results of the Netherlands Mental Health Survey and Incidence Study (NEMESIS). Soc Psychiatry Psychiatr Epidemiol 33:587-595

Boomsma DI, de Geus EJC, Vink JM, Stubbe JH, Distel MA, Hottenga JJ et al (2006) Netherlands Twin Register: from twins to twin families. Twin Res Hum Genet 9:849-857

Boomsma DI, Vink JM, van Beijsterveldt TC, de Geus EJ, Beem AL, Mulder EJ et al (2002) Netherlands Twin Register: a focus on longitudinal research. Twin Res 5:401-406

Curtis GC, Magee WJ, Eaton WW, Wittchen HU, Kessler RC (1998) Specific fears and phobias - epidemiology and classification. $\mathrm{Br}$ J Psychiatry 173:212-217

Derks EM, Dolan CV, Boomsma DI (2004) Effects of censoring on parameter estimates and power in genetic modeling. Twin Res 7:659-669

Fredrikson M, Annas P, Fischer H, Wik G (1996) Gender and age differences in the prevalence of specific fears and phobias. Behav Res Ther 34:33-39

Furmark T (2002) Social phobia: overview of community surveys. Acta Psychiatr Scand 105:84-93

Fyer AJ, Mannuzza S, Chapman TF, Martin LY, Klein DF (1995) Specificity in familial aggregation of phobic disorders. Arch Gen Psychiatry 52:564-573

Garrison RJ, Anderson VE, Reed SC (1968) Assortative marriage. Eugen Q 15:113-127

Gillespie NA, Kirk KM, Evans DM, Heath AC, Hickie IB, Martin NG (2004) Do the genetic or environmental determinants of anxiety and depression change with age? A longitudinal study of Australian twins. Twin Res 7:39-53

Hall GS (1897) A study of fears. Am J Psychol 8:147-249

Henderson AS, Jorm AF, Korten AE, Jacomb P, Christensen H, Rodgers B (1998) Symptoms of depression and anxiety during adult life: evidence for a decline in prevalence with age. Psychol Med 28:1321-1328

Hettema JM, Neale MC, Kendler KS (2001) A review and metaanalysis of the genetic epidemiology of anxiety disorders. Am J Psychiatry 158:1568-1578 
Hettema JM, Neale MC, Myers JM, Prescott CA, Kendler KS (2006) A population-based twin study of the relationship between neuroticism and internalizing disorders. Am J Psychiatry 163:857-864

Hettema JM, Prescott CA, Myers JM, Neale MC, Kendler KS (2005) The structure of genetic and environmental risk factors for anxiety disorders in men and women. Arch Gen Psychiatry 62:182-189

Jöreskog KG, Sörbom D (1996) PRELIS 2 user's reference guide. Scientific Software International, Chicago

Kendler KS, Jacobson KC, Myers J, Prescott CA (2002) Sex differences in genetic and environmental risk factors for irrational fears and phobias. Psychol Med 32:209-217

Kendler KS, Karkowski LM, Prescott CA (1999) Fears and phobias: reliability and heritability. Psychol Med 29:539-553

Kendler KS, Myers J, Prescott CA, Neale MC (2001) The genetic epidemiology of irrational fears and phobias in men. Arch Gen Psychiatry 58:257-265

Kendler KS, Neale MC, Kessler RC, Heath AC, Eaves LJ (1992) The genetic epidemiology of phobias in women. The interrelationship of agoraphobia, social phobia, situational phobia, and simple phobia. Arch Gen Psychiatry 49:273-281

Kessler RC, Berglund P, Demler O, Jin R, Walters EE (2005) Lifetime prevalence and age-of-onset distributions' of DSM-IV disorders in the national comorbidity survey replication. Arch Gen Psychiatry 62:593-602

Kessler RC, McGonagle KA, Zhao S, Nelson CB, Hughes M, Eshleman $S$ et al (1994) Lifetime and 12-month prevalence of DSM-III-R psychiatric disorders in the United States. Results from the National Comorbidity Survey. Arch Gen Psychiatry 51:8-19

Lapouse R, Monk MA (1959) Fears and worries in a representative sample of children. Am J Orthopsychiatry 29:803-818

Low N, Cui L, Merikangas KR (2007) Spousal concordance for substance use and anxiety disorders. J Psychiatr Res 41:942-951

Maes HHM, Neale MC, Kendler KS, Hewitt JK, Silberg JL, Foley DL et al (1998) Assortative mating for major psychiatric diagnoses in two population-based samples. Psychol Med 28:1389-1401

Marks IM (1987) Fears, phobias, and rituals: panic, anxiety, and their disorders. Oxford University Press, New York

Marks IM, Mathews AM (1979) Brief standard self-rating for phobic patients. Behav Res Ther 17:263-267

Mathews CA, Reus VI (2001) Assortative mating in the affective disorders: a systematic review and meta-analysis. Compr Psychiatry 42:257-262

Mendlowicz MV, Stein MB (2000) Quality of life in individuals with anxiety disorders. Am J Psychiatry 157:669-682

Merikangas KR (1982) Assortative mating for psychiatric-disorders and psychological traits. Arch Gen Psychiatry 39:1173-1180

Middeldorp CM, Birley AJ, Cath DC, Gillespie NA, Willemsen G, Statham DJ et al (2005) Familial clustering of major depression and anxiety disorders in Australian and Dutch twins and siblings. Twin Res Hum Genet 8:609-615

Muris P, Merckelbach H (2001) The etiology of childhood specific phobia: a multifactorial model. In: Vasey MW, Dadds MR (eds) The developmental psychopathology of anxiety. Oxford University Press, New York, pp 355-385
Neale MC, Boker SM, Xie G, Maes HH (2003) MX: statistical modelling, 6th edn. Richmond

Neale MC, Walters EE, Eaves LJ, Kessler RC, Heath AC, Kendler KS (1994a) Genetics of blood-injury fears and phobias: a population-based twin study. Am J Med Genet 54:326-334

Neale MC, Walters EE, Eaves LJ, Maes HH, Kendler KS (1994b) Multivariate genetic-analysis of twin-family data on fears - Mx models. Behav Genet 24:119-139

Page AC (1994) Blood-injury phobia. Clin Psychol Rev 14:443-461

Page AC, Martin NG (1998) Testing a genetic structure of bloodinjury-injection fears. Am J Med Genet 81:377-384

Posthuma D, Boomsma DI (1999) Adding non twin siblings to increase power. Behav Genet 29:366

Posthuma D, Boomsma DI (2000) A note on the statistical power in extended twin designs. Behav Genet 30:147-158

Purcell S, Sham PC (2004) Epistasis in quantitative trait locus linkage analysis: interaction or main effect? Behav Genet 34:143-152

Rebollo I, Boomsma DI (2006) Genetic analysis of anger: genetic dominance or competitive sibling interaction. Behav Genet $36: 216-228$

Rose RJ, Ditto WB (1983) A developmental-genetic analysis of common fears from early adolescence to early adulthood. Child Dev 54:361-368

Saarni SI, Suvisaari J, Sintonen H, Pirkola S, Koskinen S, Aromaa A et al (2007) Impact of psychiatric disorders on health-related quality of life: general population survey. $\mathrm{Br} \mathrm{J}$ Psychiatry 190:326-332

Skre I, Onstad S, Torgersen S, Lygren S, Kringlen E (1993) A twin study of Dsm-III-R anxiety disorders. Acta Psychiatr Scand 88:85-92

Skre I, Onstad S, Torgersen S, Lygren S, Kringlen E (2000) The heritability of common phobic fear: a twin study of a clinical sample. J Anxiety Disord 14:549-562

Stein MB, Chartier MJ, Lizak MV, Jang KL (2001) Familial aggregation of anxiety-related quantitative traits in generalized social phobia: clues to understanding "disorder" heritability? Am J Med Genet 105:79-83

Stevenson J, Batten N, Cherner M (1992) Fears and fearfulness in children and adolescents - a genetic-analysis of twin data. J Child Psychol Psychiatry 33:977-985

Sundet JM, Skre I, Okkenhaug JJ, Tambs K (2003) Genetic and environmental causes of the interrelationships between selfreported fears. A study of a non-clinical sample of Norwegian identical twins and their families. Scandin J Psychol 44:97-106

Torgersen S (1983) Genetic-factors in anxiety disorders. Arch Gen Psychiatry 40:1085-1089

Van Zuuren FJ (1988) The fear questionnaire - some data on validity, reliability and layout. Br J Psychiatry 153:659-662

Vink JM, Willemsen G, Stubbe JH, Middeldorp CM, Ligthart RSL, Baas KD et al (2004) Estimating non-response bias in family studies: application to mental health and lifestyle. Eur J Epidemiol 19:623-630

Willemsen G, Posthuma D, Boomsma DI (2005) Environmental factors determine where the Dutch live: results from the Netherlands Twin Register. Twin Res Hum Genet 8:312-317 